\title{
Biological Assay of Foot and Mouth Disease Virus (FMDV) Serotypes for Titrating BLRI Developed Trivalent FMD Vaccines Seed
}

\author{
Mohammad Showkat Mahmud*, Eusha Islam, Md. Giasuddin, Mohammed Abdus Samad, \\ Md. Rezaul Karim, Md. Zulfekar Ali
}

Research on FMD and PPR in Bangladesh, Animal Health Research Division, Bangladesh Livestock Research Institute, Bangladesh

Copyright $\mathrm{C} 2018$ by authors, all rights reserved. Authors agree that this article remains permanently open access under the terms of the Creative Commons Attribution License 4.0 International License

\begin{abstract}
Foot and Mouth Disease (FMD) is an important viral as well as transboundary disease affecting almost all cloven-hoofed animals. The aim of the present study is the focused on determination of biological titer by tissue culture infective dose ${ }_{50}\left(\mathrm{TCID}_{50}\right)$ assay of currently available FMD virus serotype in Bangladesh. For adaptation of FMD virus (FMDV), BHK-21 cell line was used. BHK-21 cell subculture was done from preserved cultured bottle of Foot and Mouth Disease (FMD) Research Laboratory of Bangladesh Livestock Research Institute (BLRI), Savar, Dhaka. RT-PCR confirmed selected three different positive serotypes (O, A and Asia 1) of FMD virus were inoculated into BHK-21 cell culture and cytopathic effects (CPE) were observed after adaptation into BHK-21 cell from $3^{\text {rd }}$ to $5^{\text {th }}$ passages. Clear infectious $\mathrm{BHK}-21$ cell culture fluid was collected and preserved at $-80^{\circ} \mathrm{C}$ temperature. The $\mathrm{TCID}_{50}$ assay was performed to determine the biological titer of the three positive serotype of FMDV. The biological titer of this study was found $10^{6.5} / \mathrm{ml}$ viral titer for O type, $10^{6.75} / \mathrm{ml}$ viral titer for A type, $10^{6.66} / \mathrm{ml}$ viral titer for Asia-1 type. These three specific serotypes can be used as vaccine seed against FMD virus. The effective vaccination of susceptible animals is considered to be the corner stone to the disease in our country Bangladesh. The findings of this study can be helpful for the trivalent vaccine development in Bangladesh and it may effective in limiting the spread of FMD.
\end{abstract}

Keywords Baby Hamster Kidney- 21 cell, Foot and Mouth Disease virus, Tissue Culture Infective Dose $_{50}$, Vaccine

\section{Introduction}

Foot and Mouth Disease (FMD) is a severe, highly contagious viral disease of livestock with significant economic impact. According to the antigenic properties of the capsid proteins, FMDVs are classified into 7 serological types, namely O, A, C, Asia 1 and SAT 1-3 [1]. Infection with one serotype does not confer immunity against another [2]. Outbreak of FMD causes severe economic losses to the livestock industries in terms of loss of draft power, meat and milk production, infant and adult animal mortality $[3,4,5]$. Annual loss due to FMD in Bangladesh has been estimated at about 62 million US\$ [6]. Like other viruses, the FMD virus continually evolves and mutates, thus one of the difficulties in vaccinating against it is the huge variation between, and even within, serotypes. There is no cross-protection between serotypes. This means FMD vaccines must be highly specific to the strain involved. Vaccination only provides temporary immunity that lasts from months to years. Although every year vaccination is carried out throughout the country against FMD, still the disease outbreak occurs in many parts of Bangladesh [7]. A recent report from FAO has recommended that surveillance and reporting of FMD need to be improved throughout the country.

To limit the spread of FMD, animal vaccination was effective for the control of FMD. This control is dependent on the potency, efficacy, and specificity of the produced vaccine, which is related directly on the infectivity and antigenicity of the vaccinal FMDV serotypes used in the vaccine. It has also been reported that with subsequent cultivation in BHK-21 clone 13 cell line, the titer of FMDV increased. To test the susceptibility for FMDV of a cell line, different serotypes of FMD viruses may serve as an indicator because this serotype has the most difficulties to grow in different BHK-21 cell lines that support the growth of all serotypes of FMDV for the production of vaccine. The present study was conducted with biological assay of three different FMDV serotypes (O, A and Asia 1) for titrating BLRI developed trivalent FMD vaccines seed in 
Bangladesh.

\section{Materials and methods}

\subsection{Source of Foot and Mouth Disease (FMD) Virus Candid's Cultivation}

Previously preserved positive samples of FMD virus $(\mathrm{O}$, A and Asia 1) were taken from the Foot and Mouth (FMD) Research Laboratory, Animal Health Research Division, Bangladesh Livestock Research Institute (BLRI), Savar, Dhaka-1341. FMD virus serotype O (FMD-BLRI 82), serotype A (FMD-BLRI 127), serotype Asia 1 (FMD-BLRI 107) were selected and inoculated in BHK-21 cell [8].

\subsection{Subculture of BHK-21 Cell}

All the media and reagents were brought to room temperature before use. The growth media containing $8-10 \%$ fetal calf serum was removed from the $25 \mathrm{~cm}^{2}$ polystyrene TPP $^{\circledR}$ tissue culture flask (Sigma-Aldrich, Europe). Then the monolayer cells were washed with sterile 1X PBS for 3 times. Trypsin ( 0.5 milliliter) was added into the flask and gentle tapping to detach the cells. The flask was left in the incubator for 2-3 min and observed under microscope. 5-7 $\mathrm{mL}$ of media containing cell was poured into flask. The flask was allowed to incubate at $37^{\circ} \mathrm{C}$ for $24 \mathrm{~h}$ [9].

\subsection{Adaptation of FMDV in BHK-21 Cell Culture}

The cells those formed confluent monolayers in the culture flask within $24 \mathrm{~h}$ of incubation were selected for infection with viruses. The growth media from the flask containing BHK-21 cell was removed and then the monolayer cells were washed with $1 \mathrm{X}$ sterile PBS for 3 times. One milliliter $(1 \mathrm{~mL})$ of virus inoculum was added to the $25 \mathrm{~cm}^{2}$ polystyrene $\mathrm{TPP}^{\circledR}$ tissue culture flasks (Sigma-Aldrich, Europe). The inoculum was spread over the monolayer cell by tilting for about 45-60 min for the establishment of better interaction. Then 5-8 mL maintenance media was added in flask and the vessel was returned to the incubator at $37^{\circ} \mathrm{C}$ for $1-2$ days. Virus added flask was allowed to incubate at $37^{\circ} \mathrm{C}$ for $1-2$ days. The cells were examined twice daily under inverted microscope until showing characteristic cytopathic effect (CPE). A control monolayer cell also was maintained. After completion of CPE, infected cell culture bottle along with control cell monolayer were stored at $-20^{\circ} \mathrm{C}$. The cell culture supernatant was harvested by repeated freezing and thawing for 3 to 4 times and the cell suspension was clarified by centrifugation at $5,000 \mathrm{rpm}$ for $15 \mathrm{~min}$ at $4^{\circ} \mathrm{C}$. The supernatant collected was stored at $-80^{\circ} \mathrm{C}$ [9].

\subsection{Tissue Culture Infective Dose ${ }_{50}\left(\mathrm{TCID}_{50}\right)$ Determination Procedure}

After incubation periods, cytopathic effects (CPE) of the virus was observed under inverted microscope and the harvested culture fluid was processed for biological titration $\left(\mathrm{TCID}_{50}\right)$ [10]. In steps one, at first a monolayer flask was taken from incubator and trypsinized for cell detachment. Then detached cell was transferred to sterile media tray. After that, $100 \mu 1$ of cells were distributed with Growth media in Microtest ${ }^{\mathrm{TM}}$ 96-well tissue culture polystyrene Nunc plate (Becton Dickinson, USA) and the plate was incubated at $37^{\circ} \mathrm{C}$ until confluent monolayer cells in each well of plate. In steps two, virus suspension was diluted 10 fold dilution, using $\mathrm{TCID}_{50} 96$ wells round bottom plate (tips change mandatory in every step). In steps three, $25 \mu 1$ infections were added to the $\mathrm{TCID}_{50} 96$ wells flat bottom plate and leave last 2 columns of the plate for use as control. The Microtest ${ }^{\mathrm{TM}}$ 96-well tissue culture polystyrene plate (Becton Dickinson, USA) was incubated at $37^{\circ} \mathrm{C}$ for 48 hours and observed under inverted microscope (Leica DMil, Germany). Then, the number of positive and negative wells was recorded. Tissue Culture Infection Dose $_{50} / \mathrm{ml}\left(\mathrm{TCID}_{50} / \mathrm{ml}\right)$ refer to virus particles per $\mathrm{ml}$ which can produce $\mathrm{CPE}$ at 50 percent inoculated cells, calculated by the Reed \& Meunch method [11]. The titer of virus was calculated by using the following formula.

A) Calculation of proportionate distance (PD) between the two dilution above and below $50 \%$ end point

$\mathrm{PD}=\frac{\% \text { positive at or above } 50 \%-50 \%}{\% \text { positive at or above } 50 \%-\% \text { positive below } 50 \%}$

B) Calculation of $50 \%$ endpoint titer

$50 \%$ endpoint titer (TCID 50/0.1 $\mathrm{ml}$ ) $=10^{\log \text { total dilution above }}$ $50 \%$-[PD* $\log$ (dilution factor)]

\section{Result and discussion}

\subsection{Selection of Three Serotype of FMDV}

Three FMDV positive samples were randomly selected from serotype $\mathrm{O}, \mathrm{A}$ and Asia 1, and then inoculated in BHK-21 cell line. Type O (FMD-BLRI 82), Type A (FMD-BLRI 127), Type Asia 1 (FMD-BLRI 107) inoculated in BHK-21 cell and CPE was observed [9].

\subsection{Adaptation of FMDV and CPE Observation}

The virus inoculum (serotype $\mathrm{O}$, A, Asia 1 positive) did not induce any toxic effects on the cells and cytopathic effect (CPE) could be observed on first passage onwards. Propagation of FMDV in BHK-21 cell was confirmed by appearance of CPE comprising rounding and flattening of the cells, breaking down of the intracellular bridges and 
finally cell death. The findings of cell culture following infection with FMDV were similar with the findings of Hossen et al. [12], Islam et al. [13], Shahiduzzaman et al. [14], Alam et al. [15]. BHK-21 cells were often chosen as a simple in vitro model for analysis of the direct viral influences on host cell protein machinery, and routinely used for FMDV pathogenic research [16-18]. Reproduction of FMDV reached plateau period and CPE is the most obvious during $12 \mathrm{~h}$ infection. So, the time at $12 \mathrm{~h}$ post infection was selected. Characteristic CPE appeared by $12 \mathrm{~h}$ post infection, within $48 \mathrm{~h}$ more than $60 \%$ cells died and by $72 \mathrm{~h}$ cell monolayer detached from the surface of the culture vessels. Along with passage of virus CPE appeared earlier and complete CPE could be detected by 24 $\mathrm{h}$. The virus was readily adapted to BHK-21 cell line within first 3 passages.

\subsection{Determination of Biological Titer by TCID $_{50}$ Assay}

$50 \%$ Tissue culture Infective Dose $\left(\mathrm{TCID}_{50}\right)$ is the measure of infectious virus titer. This endpoint dilution assay quantifies the amount of virus required to kill $50 \%$ of infected hosts or to produce a cytopathic effect in $50 \%$ of inoculated tissue culture cells.

Table 1. The titer values of these three serotypes were as follows

\begin{tabular}{|c|c|}
\hline Serotypes & TCID $_{50}$ \\
\hline O Type & $10^{6.5} / \mathrm{ml}$ viral titer \\
\hline A Type & $10^{6.75} / \mathrm{ml}$ viral titer \\
\hline Asia 1 Type & $10^{6.66} / \mathrm{ml}$ viral titer \\
\hline
\end{tabular}

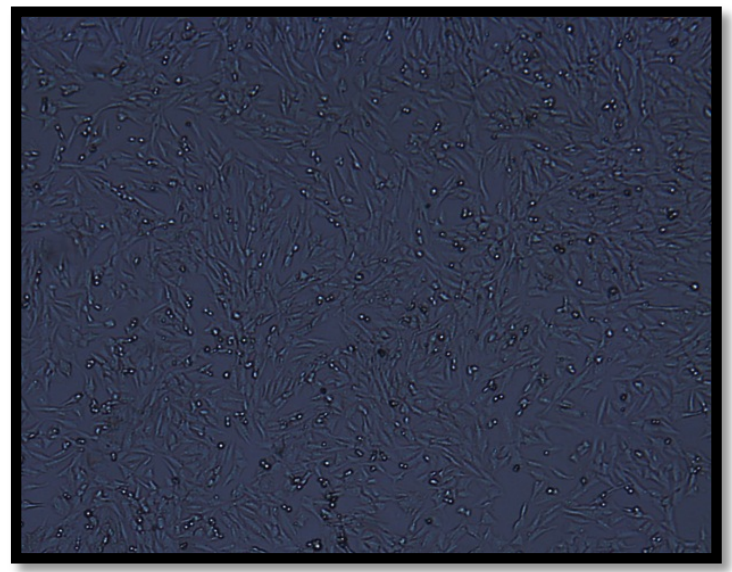

The present study was undertaken to identify the FMDV serotype "O", "A" and "Asia 1 " from different districts of Bangladesh in 2013 to 2014. It will help for evaluation and molecular characterization of currently available foot and mouth disease virus in Bangladesh for the development of vaccine to improve the economy of the farmers. Three FMDV samples were randomly selected from serotypes $\mathrm{O}$, $A$ and Asia 1 (Type O: FMD-BLRI 82, Type A: FMD-BLRI 127, Type Asia 1: FMD-BLRI 107), then inoculated in BHK 21 cell line [9].The cytopathic effect (CPE) produced by the inoculum of FMDV in BHK-21 cell were manifested by the rounding and flattening of the cells, breaking down of the intracellular bridges and finally cell death which are characteristic findings of FMDV infected cells. These results are also supported by Quddus et al. [19] who also used BHK 21 cell line for FMD virus adaptation. The findings of cell culture following infection with FMDV were similar with the findings of Hossen et al. [12], Shahiduzzaman et al. [14], Alam et al. [15]. The TCID 50 assay was performed by using tenfold serial dilutions of the virus sample, and plates those samples in quadruplicate in Microtest $^{\mathrm{TM}}$ 96-well tissue culture polystyrene plate (Becton Dickinson, USA). The biological titer from this study found $10^{6.5} / \mathrm{ml}$ viral titer for O type, $10^{6.75} / \mathrm{ml}$ viral titer for A type and $10^{6.66} / \mathrm{ml}$ viral titer for Asia- 1 type. These three specific serotypes can be used as vaccine seed against FMD virus. Chowdhury et al. [20] showed that the result of $\mathrm{TCID}_{50}$ was $10^{8.5} \mathrm{TCID} / \mathrm{ml}$ for O serotype, $10^{7}$ $\mathrm{TCID}_{50} / \mathrm{ml}$ for A serotype and $10^{7.5} \mathrm{TCID}_{50} / \mathrm{ml}$ for Asia- 1 . This result is greater than from our $\mathrm{TCID}_{50}$ result.

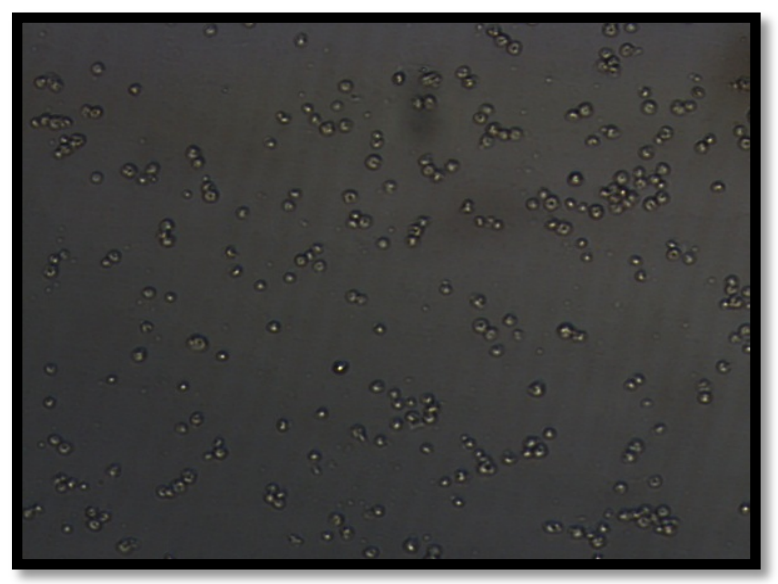

Figure1. Normal BHK-21 cell (left) and BHK-21 cell showing rounding of cell after inoculation of the virus (right) observed under 40X objective (Leica DMil, Germany). 


\section{Conclusions}

Foot and Mouth Disease (FMD) is prevailing in cattle and buffaloes and is mainly caused by either O, A, Asia-1 serotype of the FMD virus in Bangladesh. The main focus of this study was to isolate circulatory Foot-and-Mouth Disease Virus from infected cattle and adaptation of FMD virus (FMDV) in BHK-21 (Baby Hamster Kidney) cell line for determination biological titer. BHK-21 cells are critical factors for supporting maximum infectivity titer of FMD virus serotypes. In future, the research findings may be used for the preparation of trivalent vaccine against FMDV in Bangladesh to improve the potency of the FMD vaccine produced.

\section{Acknowledgements}

The research was funded by the development project of "Research on FMD and PPR in Bangladesh" (Award no. 7080) of Ministry of Fisheries and Livestock, Bangladesh.

\section{REFERENCES}

[1] M. Mittal, C. Tosh, D. Hemadri, A. Sanyal and S. K. Bandyopadhyay. Phylogeny, genome evolution, and antigenic variability among endemic foot-and-mouth disease virus type A isolates from India. Arch. of virol., 150(5): 911-928, 2005.

[2] OIE. Principles of Veterinary Vaccine Production. In: Manual of Diagnostic Tests and Vaccine for Terrestrial Animals. Version adopted May 2006.Chapter 1.1.7, 2009.

[3] S. M. Z. H. Chowdhury, M. F. Rahman, M. B Rahman, and M. M. Rahman. Foot and mouth disease and its effects on morbidity, mortality, milk yield and draft power in Bangladesh. Asian. Austra. J of Ani. Sci., 6(3): 423-426, 1993.

[4] M. A. Zinnah, M.T.Islam, M. M. Rahman, M. T. Hossain, M. A. Zinnah, M. R. Bari, M. H. Haque, M. S. R. Khan and M. A. Islam. Standardization of Multiplex Reverse Transcription Polymerase Chain Reaction and typing of Foot-And-Mouth disease virus prevalent in Bangladesh. B. J of Vet. Med., 8: 149-155, 2010.

[5] G. Belshamand A. Bøtner. Use of recombinant capsid proteins in the development of a vaccine against foot-and-mouth disease virus (FMDV). Vir. Adapt. and Treat., 7:11-23, 2015.

[6] FAO/OIE. FMD virus pools and the regional programmes. Virus Pool 2- South Asia, 2012.

[7] S. Sarker, S. Talukder, M. H. Haque, M. H. Islam and S. D. Gupta. Epidemiological study on foot and mouth disease in cattle: prevalence and risk factor assessment in Rajshahi, Bangladesh. Wayam. J. of Ani. Sci., 3: 71-73, 2011.

[8] M. Giasuddin, M. S. Mahmud, S. M. S. Alam, M. A. Samad, M. R. Islam, M. D. Ahasan, M. H. Rahman, M. R. Karim, M. R. Islam, P. Acharjee and M. A. Yousuf. Molecular
Epidemiology of Foot-and-Mouth Disease Viruses Circulated in Bangladesh from 2011-2014. Brit. Micro. Res. J., 16(4):1-13, 2016.

[9] M. S. Mahmud, E. Islam, M. A. Samad, M. R. Karim, A. K. Saha and M. Giasuddin. Adaptation of Three Different BLRI Strain (O, A, Asia 1) of Foot and Mouth Disease Virus Serotypes in Baby Hamster Kidney-21 Cell Line. Immun. and Infect. Dis., 5(2): 11-15, 2017.

[10] S. Alhaji. A modified arithmetical method of Reed and Muench for determination of a relatively ideal median lethal dose (LD50).Afric. J. phar. and pharma., 5(12): 1543-1546, 2011.

[11] L. J. Reed and H. Muench. A simple method of estimating 50 peresent end points. Am. J. Hyg. 27: 493- 497, 1938.

[12] M. L. Hossen, S. Ahmed, M. F. R. Khan, M. T. Rahman, S. Saha, K. H. M. N. H.Nazir, M. Rahman, M. A. Islam, M. B. Rahman. Typing of Foot and Mouth Disease Virus Circulating in Bangladesh by Reverse Transcription Polymerase Chain Reaction. J. Vet. Adv., 4(12):778-785, 2014.

[13] M. A. Islam, M. M. Rahman, K. H Adam, O. Marquardt. Epidemiological implications of the molecular characterization of foot and mouth disease virus isolated between 1996 and 2000 in Bangladesh. Vir. Gen., 23:203-213, 2000.

[14] A. N. Shahiduzzaman, M. E. Haque, M. H. Rahman, M. F. Khan and M. B Rahman. Serotyping and Adaptation of Foot and Mouth Disease Virus in BHK-21 Cell Line towards the Development of Vaccine Candidate. Inter. J of Vac., 3(2): 00060, 2016.

[15] M. A. Alam, M. Rahman, M. L. Hossen, S. Ahmed, M. S. Parvej, M. F. R. Khan, M. B. Rahman. Reverse transcription polymerase chain reaction (RT-PCR) based detection and serotyping of FMD Virus from field samples of Gazipur, Bangladesh and adaptation of the virus in BHK-21 cell. J. Adv. Vet. Anim. Res 2(3): 291-295, 2015.

[16] K. U. Anil, B. P. Sreenivasa, J. K. Mohapatra, M. Hosamani, R. Kumar, R. Venkataramanan. Sequence analysis of capsid coding region of foot-and-mouth disease virus type A vaccine strain during serial passages in BHK-21 adherent and suspension cells. Biologicals: J. Int. Assoc. Biol. Stand. 40:426-30, 2012.

[17] W. Chen, W. Yan, Q. Du, L. Fei, M. Liu, Z. Ni, Z Sheng, Z. Zheng. RNA interference targeting VP1 inhibits foot-and-mouth disease virus replication in BHK-21 cells and suckling mice. J. Virol., 78:6900-7, 2004.

[18] X. Huang, Y. Li, H. Fang, C. Zheng. Establishment of persistent infection with foot-and-mouth disease virus in BHK-21 cells. Virol. J., 8:169, 2011.

[19] M. R. Quddus, M. L. Hossen, M. M. R. Chowdhury, T. Chakrobarty, S. Mahmud, K. H. M. N. H. Nazir, K. M. Nasiruddin, M. B Rahman. RT-PCR based detection and adaptation of foot and mouth disease virus serotype " $A$ " in BHK-21 cell line. Progre. Agri., 27: 64-69, 2016.

[20] M. M. R. Chowdhury, M. L. Hossen, S. Ahmed , K. H. M. N. H. Nazir, M. Rahman, M. F. R. Khan, K. B. Amin, M. T. Rahman and M. B. Rahman. Preparation of Inactivated Trivalent FMD Vaccine and Determination of Antibody Titre in Vaccinated Cattle, J. Adv. Vet. Anim. Res., 16(2): $1-8,2016$. 